Mansoura Engtneertng Journat (MEJ), Vo1.20, No, 4, Dec. 1995 E. 24

\title{
A framework for improving software reusability within quality constraints
}

$$
\text { إطار عمل لتحسين إعادة إبتثلدام البريجيات في حلدود متطليات الجردة }
$$

\section{Guirguis S.K.}

Institute of Graduate Studies \& Research, Alexandria University, Egypt.

$$
\begin{aligned}
& \text { ملنخص }
\end{aligned}
$$

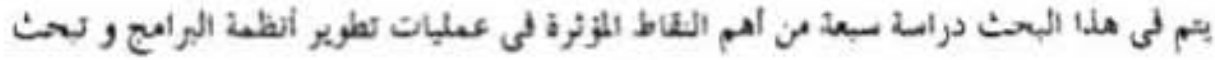

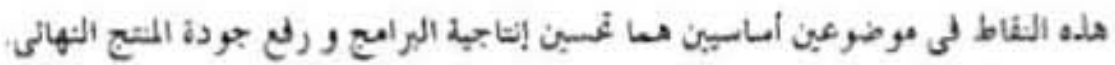

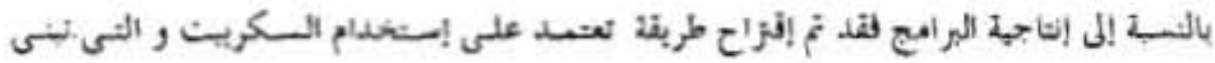

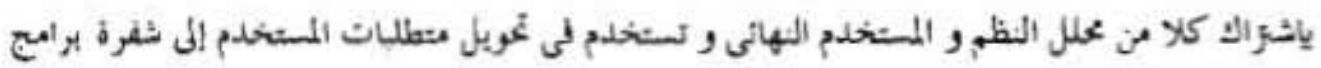

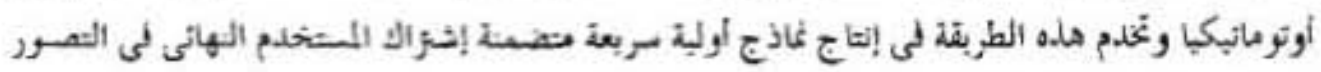

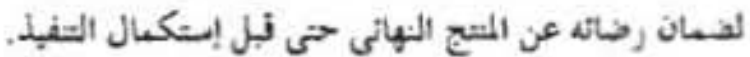

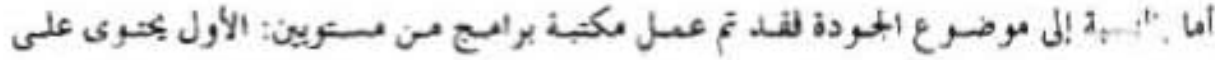

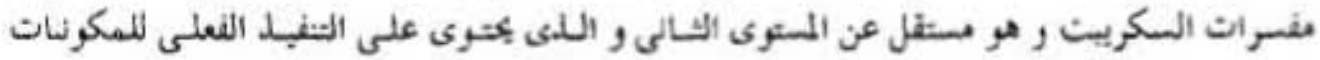

$$
\begin{aligned}
& \text { المزدية }
\end{aligned}
$$

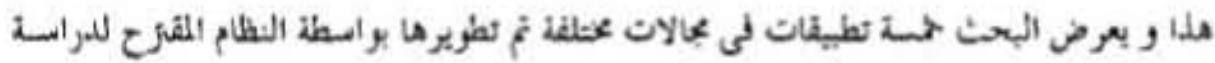

$$
\begin{aligned}
& \text { حلدواه. }
\end{aligned}
$$

\section{ABSTRACT}

In this paper seven of the most important issues in software systems development bave been investigated. These issues address two aspects, namely: software development productivity and the final product overall quality.

For the productivity aspect, an approach has been devised relying on using scripts. Built as a result of an analyst-user collaboration, these scripts, upon interpretation, transform given user requiremeats into code. This prototyping approach, in addition to being rapid, invelves the user in order to ensure his overall satisfaction with the final product. 


\section{E.25 S, K.Gu1rguis}

For the quality aspect, a two-lnyerid repository of thoroughly tested and verified reusable software components bas been bailt. The first layer contains the keraels to interpret the scripts. This is independent of the physical implementation of the functional components in the second layer. Usiag the repository, the care data manipulations of virtually any application can be antematically generated.

Five applications covering five different domalns bave been desigaed and implemented to investigate the merits of the above described framework.

\section{INTRODUCTION}

It is ooticenble that one of the most tmportant goals of sofware systems develepers is to be able to directly traasiate given user requiremeats into cotapater code. This direct translation ains at minimizing the development effort and time as well as achieving maximum aser satisfaction. In this paper we are concerned with some of the key techniques and attributes that must be considered to fulfill the above mentioned goal, namely:

- Standardized user interface.

- Unification of data manipulation methods.

. Rapid software prototyping.

- Compilation of repositories of reusable software components

. Software system maintainability and modifiability.

. Final product reliability.

Dne to the nature of query/response and storage/retrieval information systems, the above described issoes are likely to be directly realized to some extent. Other systens sach as data acquisition are mostly domain depeadent and therefore special coding is mandatory.

\subsection{User interface}

Design of the user interface is getting more and more stabilized through the implementation of well recognized and widely used tecbriques, eg. pop-up and paltdown menus, context sensitive belp screeas, bot keys, windows ... etc. (See for example (11). Employing such techniques ensures, to some extent, familiarity of the aser with navigating through the system's various functions.

\subsection{Data manipulations}

Data manipulations generally coastitute the greatest proportion of the code size and ran time of many lafe mation systems [2]. For this couslderatloa, receat programming environments include varlous built-in data bandling mechanisms. However, some programming effort is generally required to customize data eatry forms that include application-specific manipulations.

Afthough linking and data processing routines are special cases that must be bandled separately, in the current proposed approach, these bave been treated as modales that could be added during any stage of the system development. The latter 
point is rather facilitated due to the extensive use of scripts that internally characterize the proper data type transformations, leaving the developer with only specifying the required data flows and specific algorithms. This attempt is likely to satisfy the three key features of an automatic programming system under data manipuiations context [3].

\subsection{Rapid software prototyping}

In its early days form, it would have taken the developer quite some time to design the data eotry layouts and the reporting formats to get the user's approval on a proposed software system. The prototype's essential role is therefore to assess the merits as well as the pitfalls of a proposed software system before actually going into the more complicated processes and details of designing and implementing the full system. These bave evolved chiefly due to:

- the timing constraint normally imposed over software systems development, and , the occasionally unciear software requirements specification.

The latter point is partially attributed to the user who is nof acquainted witb expressing bis requirements in techoically acceptable terms, as well as it is attributed to the analyst himself, who is sometimes not aware of tbe user's real problem. Severai attempts are being made in formalixing users' requirements in acceptable tecbnical terms for the benefit of both contracting parties (See for example [4,5]). Rapid software prototyping can aid in at least the following phases:

- gettiog the user to approve (or disapprove) a proposed software system in the earliest stage possible,

. if the system is disapproved, its design can be modified and proposed again until eventually its framework is accepted, and

- upon approval, the user is enabled to start feediog-in his data sets wti. the rcs: of the software system is still being developed.

This approach has a profound impact on reducing the software development lifecycle. Quality of the fieal product, however, must be maintained $[6,7]$.

\subsection{Software reusability}

Another very important issue to be considered is that whether the development process would start from scratch or rely on a repository of thoroughly checked reusable software components [8]. These components are verified and validated against test data patteras in a fasbion similar to trouble-sbooting in bardware component testing.

\subsection{Maintainability and modifiablity}

In the current context, a software system is considered maintainable when each of its components can be isolated and verified. It is considered modifiable when all alterations can be made at the system definition level rather than the component or the instruction level. One of the aims of structured analysis and design is to enable maintenance and modification of software systems in an easy manner. Techniques employed in Computer Aided Software Engineering are therefore appreciable (See for example $(9,10])$. 


\section{E.27 S.K. Cu1rguta \\ 1.6. Reliability}

It is generally important to be able to quantify reliability in order to judge the overall performance of a given software system. However, comparing two software systems is not a straight forward process. Lockhart [11] pointed that there is no such thing as a geueral purpose model of systcm reliability. Macro and Buxton [12] have associated reliability with compliance and modifiability. They bave noticed tast modifiability, and consequently reliability, are left with no real metrics. They have also coneluded that the already known measures such as MTBF and MTTR, although suecessfully applied to bardware systems, are not adequate for software systems reliability evaluation.

On the road to quantify software reliability, Geist et al. [13] have been interested in $N$ version, real-time software reliability estimate. In their tudy, they have used a graphical Petri net simulation tool that included arbitrary firing time distribution and correlated firing. The model has been used to estimate MTTF using mutation analysis applied to a simple wodel.

In this paper we introduce a performance index $(\theta)$, defined as the ratio between the probability of failure of a systematically built software system and its worst case value if the system is built from serateh. This approach has been used to assess the gained performance when relying on repositories of reusable software components.

\section{AIM OF THE WORK}

This paper suggests a framework for software systems development bearing in mind the above mentioned facts. Other complementary features that have been taken into consideration throughout the development process are also presented and diseusscd.

\section{CASE STUDIES}

In order to assess the merits of the proposed framework, the implemented software has been applied to five case studies. It has been used to generate five applications in five different domains:

1. Scientific: Questionnaire data manipulation and processing. Given the acronym (QUTRE) standing for: Questionnaire Utilization in an Integrated

Tabulation Environmest.

2. Industrial: Machine Service Log and follow-up (MSL).

3. Commercial: Coutainer Loading/Unloading Control (CLUC).

4. Maangerial: Assets Control System (ACS).

5. Social: Social Development Crganization providing aid to the needy (SDO).

\section{IMPLEMENTATION}

In tbis work a repository of software components has beee built (Figure 1). It can be logically separated into two layers: 
Layer 1:

Consists of the system keraels used to interpret the scripts. These scripts are designed to contain menu definitions and procedural flow. The system kernels are:

- Data manipulation program generation keroel

- Query formation kernel

. Report generation kernel

Layer 2:

Contains the lower level procedures, functions and macros to be expanded as appropriate by layer. 1 . It must be noted that the same data usnipulation procedures and imacros are re-used for query formation and report generation.

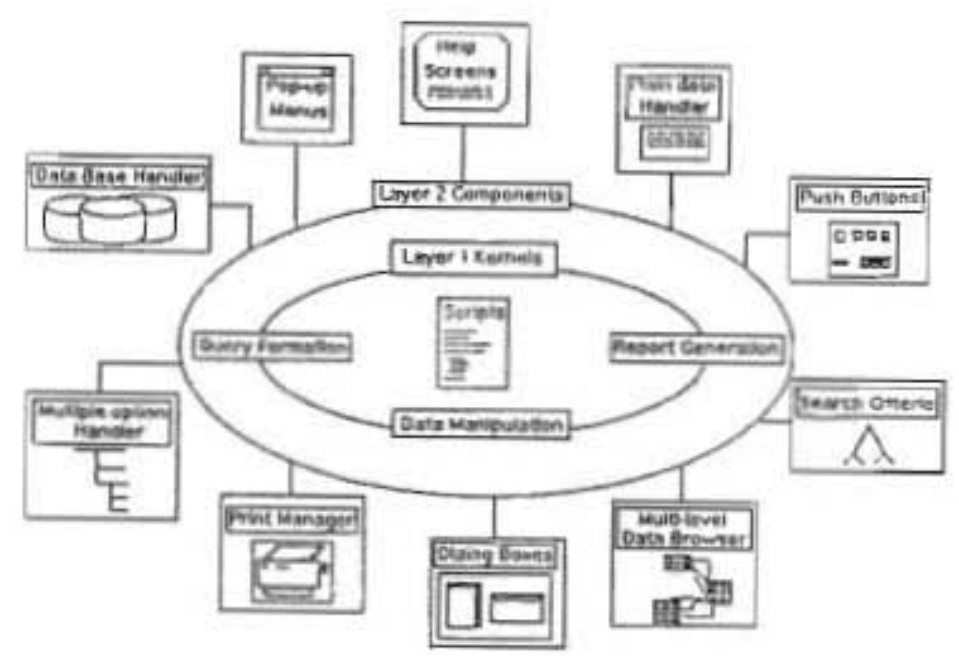

Figure 1. Logical overview of the proposed system

Layer 2 includes procedures to bandle the possible data manipulation responses described in Table (I) given below. These procedures can bandle plain, single option, multiple option and key entries.

Anotber feature bas been added wbere a given response is designated a pusb button that activates a sub-process. This sub-process is typically a lower level data manipulation routine that babdles transactions (or details) concernisg the parent data base. Tbis process is repetitive and logically unlimited. The system keeps track of the lioks between the parent, cbildren and grandcbildren data bases. 


\section{E.29 5, K. Gutrgusa}

This layer separation in the repository guarantes that the eaechanisen of autematically generating programs is isolated froen their actual pbysical implementation. This enhances the tailoring process to a preat extenc. For examples a user who requires to handle the employees' time aheet hourly rather thas dady (es, in a typical payroll systen) would need only some amendments to loyer 2 that have as effert on layer 1.

\subsection{User interface}

The user interface is zenerated frow the script that contains all menu definitions and their associated attributes. The interface employs standard techniques anch ast

. Pop-up and pull-down menus.

. Push buttons

- Content sensitive help

- Hot keys

In addition, most data entry operations, other than plain catries, are perfarmend by scrolling all possible responses on display. The wer is asked to choese ene. This speeds up data entry operatien and elimiaates bumas crors sech as cheosing errunceus codes.

\subsection{Data manipulatien}

In order to handle various problem catrgaries in almost a unified manoer, common data manipulations must be recognized in terans of dats types and peasllie user responses. Table (I) summarizes the most observed responses at fine data entry lesel.

Table L. Most common responsea te data entry procedures

\begin{tabular}{lccc}
\hline \hline & \multicolumn{3}{c}{ Data type } \\
Common response & String Integer Real Date Boelean \\
\hline $\begin{array}{l}\text { Plain entry/update } \\
\text { Siagle option }\end{array}$ & $\sqrt{ }$ & $\sqrt{ }$ & $\sqrt{ }$ \\
Multiple options & $\sqrt{ }$ & $\sqrt{ }$ & \\
Key & $\sqrt{ }$ & $\sqrt{ }$ & $\sqrt{ }$ \\
\hline
\end{tabular}

Most industry standard software packages are well equipped with precedure te bandle plain entries/updates. However, the ether possible resporser are generally left to the programmer to bandle, especially for maltiple optioa and key entries.

In the implemented system single options, maltiple options and key responses are handled as follows:

\section{a. Single option entries}

These are characterized by a limited set of possible responses, where an index (or corresponding code) is actually manipulated and stored. In order to minimize the chances of occurrence of possible data entry errors in such coded fields and to speed ap 
data entry process, ficlds of type single option are bandled such that: possible answers are displayed and serolled against the user until one is selected. The index or code of the selected response is internally transferred to the data file instead of allowing the user to enter the code himseli. This approach goes in harmony with the user interface that uses pull-down and pop-up menus.

\section{b. Multiple option entries}

Multiple option entrics can accept compound items that are mainly used in searcbing and reporting. Possible answers in ruultiple option fields are popped-up as help screens for data entry. A single code composed of 0 's or N's for not selected and digits indicating the rank of selected options is supplied by the user. Also, while editing search classes, queries of the form $\mathrm{Y} 12 \mathrm{XN}$ for instance can be formed where :

Y: means first option is seiected (no matter what's its rank)

1: means second option is ranked 1

2: means third option is ranked 2

$\mathrm{X}$ : means ignore fourth option

$\mathrm{N}$ : means fifth option is not selected nature.

This gives a noticeable flexibility in updating and analyzing data of this particular

\section{c Key entries}

Key option entries prompt the user with an identification of the data item under consideration. When appropriate, authorized users are allowed to interactively add new entries.

\subsection{Reusahle software components}

\subsubsection{Query formation}

Queries are built the same way data are entered where all features of data entry and update are ayailable. In a QBE manner, templates (typically the same data entry screens) are used for building such queries. The only difference exhibited is in the use of relational operators to build search classes. All relational operators $(>,=, \ldots$ etc.) are displayed as (GREATER THAN, IS ,... etc.) and scrolled on the data entry line for easy selection and to enhance readability. The system then generates criteria upon which queries are performed.

\subsection{2: Report generation}

Report gencration uses the same conccpts of queries. Reports are built with the classical attributes: title, subtitles, column contents, formats and filtration criteria. The other added features include:

- Field contents are automatically obtained from related data files to replace codes of single options, multiple options and keys. This feature enhances the produced report readability. 


\section{E. 31 S.K.Gulrguis}

- Filtration criteria are pre-designated and stored, however, they can be interactively altered through the use of query formation sereeas. The raodified report attributes together with a user selected report designation ean then be stored for later use. In this process an indefinite number of reports can be interactively designed and stored. This gives another dimension to the produced system flevibility.

\subsection{Prototyping}

The use of scripts facilitated generation of all data manipulation parts of the software system to the furthest extent. For instance, table (In bighlights the att. ibutes of a typical script that are required to generate data storage and retrieval programs. The same script is eventually used to interactively form queries. Simi:-it scripts are used to generate reports and menus.

The above described scripts are interpreted by the system kernels to generate the core data manipulation procedures upon which a user approval ran be obtained. Sin.e reading a script is naturall, easier than understanding code, this prototyping approach is expected to involve the user in the early requirements specification phase. Eventually, an approval can be obtained on scripts ratber than relying on sereen demonstrations.

Table IL. Typical attributes of data storage/retrieval programs

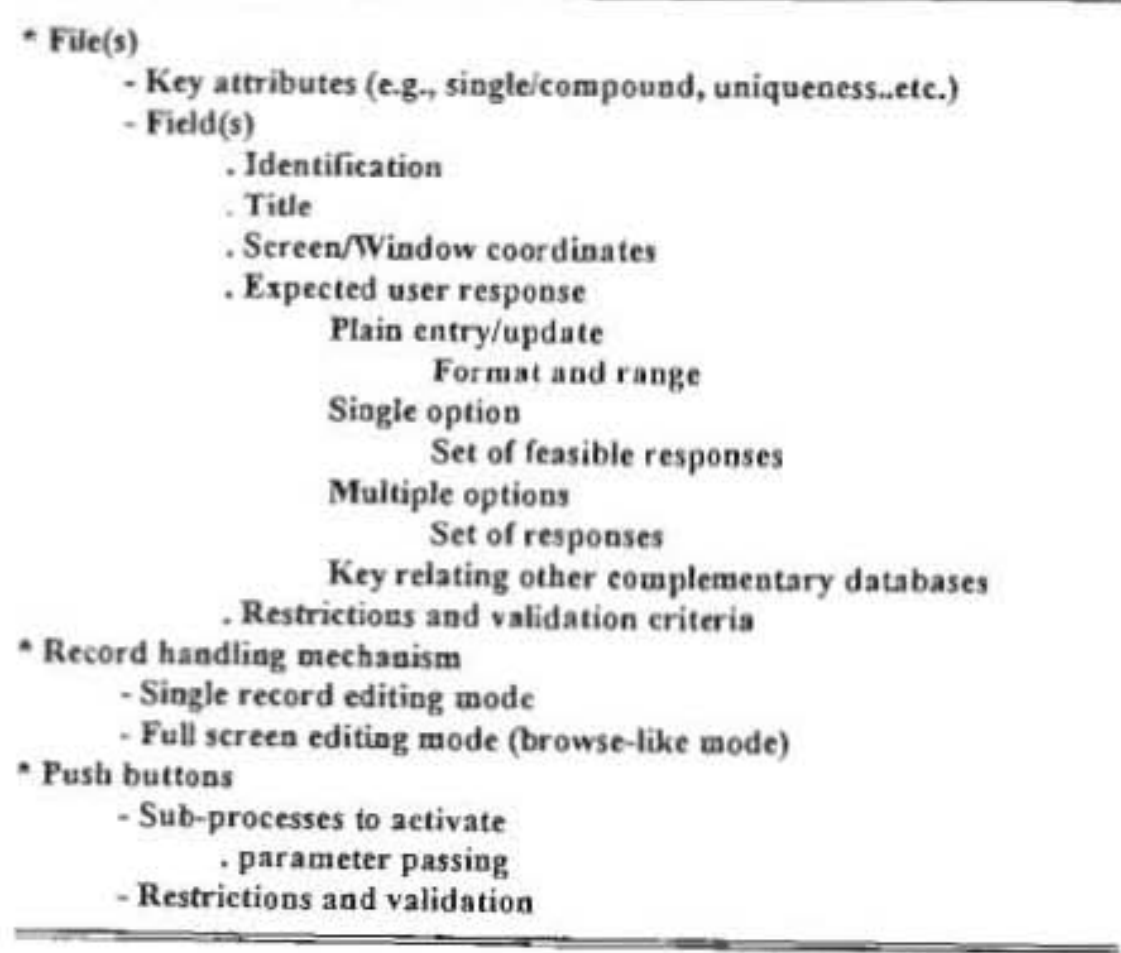


Any problem that may occur can be traced back to either the kernets of layer 1 or the components of layer 2. Any cbanges in these two layers are mapped directly to the whole system. Therefore, maintainability is assured through reviewing a limited set of procedures and routines rather than the detaiicd software system. After corrections are made to the procedures, the whole, or the affected part of tbe software system, can then be regenerated in a compilation-tike process.

\subsection{Modifiability}

This is aiso assured through the use of scripts. Any modifications are done at the definition level by updating the limited set of scripts that characterize the software system. This process can be performed iteratively and an updated software system can be immediately re-generated, untid the user is evcntually satisfied.

\subsection{Reliability}

Reliability (R) is defined in this work as the probability that the system will not fail (1- $\left.\mathrm{P}_{f}\right)$. This can be given by equation (1) where $\mathrm{P}\left(\mathrm{faii}_{\mathbf{1}} \mathrm{P}_{i}\right)$ is the probability that the whole system will fail given that process (i) of the $\Omega$ processes has failed.

$$
\mathbf{R}=1-\sum_{1}^{\Omega} \mathbf{P}\left(\text { fail } \mid \mathbf{P}_{\mathbf{i}}\right) \cdot \mathbf{P}_{\mathbf{i}}
$$

Equation (1) is valid for single processor asachines since no worc than wos process can fail at a given time. A lower limit of reliability cas be given by: $\left(1-\Sigma P_{i}\right)$. When using reusable software components the value of $\mathrm{Pi}$ can be individually reduced througb appropriate vcrification. Also, in modular design, the aumber of redundant components is reduced to its lowest limit. The net result is an increase in reliability.

Althougb thoroughly tested and verified, re-usable software componeats may fai against special cases. Let us assume that the upper bound of probability of failure of such components is given by $\mathrm{P}_{0}$, and the number of procedurcs in these components is denoted by $\sigma$ among the overall system procedures $\Omega$. Let us also assume that there exists an upper bound $P_{a}$ denoting the probability of failure of externally added components. It is likely tbat $P_{0} \ll P_{a}$. Assuming tbat $P_{a}=\alpha \cdot P_{0}$ wherc $\alpha$ is generally $>1$, probability of failure can be written as:

$$
\mathbf{P}_{\mathbf{f}}=\sigma \mathbf{P}_{0}+(\Omega-\sigma) \alpha \mathbf{P}_{0}
$$

Let us define $(\theta)$ to be the ratio between $P_{f}$ given in equation (2) and its expected value in case when the whole software system would be constructed from scratch. This is given by equation (3): 


$$
\theta=1 \cdot \frac{(\alpha-1)}{\alpha} \cdot \frac{\sigma}{\Omega}
$$

Eqquation (3) bas been applied to the five case studies. Obtained $\theta$ values are considered indicators to how much the probability of failure is generally decreased when heavily employing thoroughly tested reusable software components.

\section{APPLICATIONS AND RESULTS}

Following, is a brief review of applying the framework described above to five case studies. The case studies have been chosen to cover five different application domains as mentioned earlier.

Without loss of generality, oniy the first application will be described in some details to illustrate the ideas behind the proposed franework. In fact, it was Uhe first application that gave us the motivation to outline the suggested software development framework.

Application I. Questionnaire data manipulation and processing (QUITE):

Problem definition: A user who requires to perform some questionasire analysis would need to use an iadustry-standard software package to carry out the required statistical analyses. This way seem to be the most efficient way to perform the snalyses, but this is not always the case, since most of the availabie ready-made packages require specific structures for the input data to be maintained $[14,15]$. Analyzing combined text, numerie, boolean and date types of data is not always possible, and if available the user often suffers from a considerable burden witb regard to defining the data types and their bandliag scbemes. This may request that the user be extremely experienced in the use of a certain statistical package and may also inelude some programming effort to be done. Often, data type transformation routines are etoployed to convert from questionnaires' isternally archived data elements to suitable formats for input to a specific statistieal package. It has been decided to tailor such a software system using the framework described earlier.

\subsection{Design phase requirements} follows:

The main objectives of the system design to be realized are summarized as

1. As data structuring may constitute a problem for a given user, be is not sabjected to the internal archive structure of the questionaaire design. Also the design must fulfill the requirements of being easily maintainable and modifiable according to specific user needs. The user is only required to specify bis data items in an abstracted maneer and 
Mansoura Englneering Journal (MEJ), Vol.20, No.4.Dec.19y, E. 34 the software system is to generate the appropriate formats. Only plain text entries require the user to supply their maximum expected leogths.

2. Required to automatically, or at least easily, gencrate the data entry and editing subsystem according to the questionnaire deseription given in step 1. This saves the effort required in an esseatial, but tedious. phase. Also, it must have the advantage of beiog seif modifiable according to any alterations made in step 1 .

3. Required to inelude techviques for sandling various types of data, especially for combined analysis of multiple option entries and for performing the appropriate data transformations. These data type transformations must be accomplished iuternally without any user intervention.

4. Provide tools to allow the user to synthesize data filters used to extract study-specific subsets of data, or more widely to identify scarch classes. These tools are expected to utilize natural language specification and simple relational algebra.

5. Allow the user to easily design and produce reports of analyzed data in a selfdocumented manner to reduce the effort usually associated with producing reports for timely information distribution.

In short, the overall objective is to create an integrated environment for questionnaire data archiving and manipulation, starting from the design phase of a questionnaire form to the actoal production of analyzed data in an easily readable format.

It is wortb noting that the above requirements are generally applicable to a wide class of information systems other than this specific example. This fact has raen taken care of during the design and implementation phases. This issue resulted in an attempt to coustruct a repository of reasable software components. It also stimulated the need to identify which components are to be automatically generated and wbicb are not. Tbe rest of the case study illustrates this point.

\subsection{System design approach}

Design of QUTTE software system is organized as follows:

1. Questionnaire build-up phase

II. Automatic generation of data manipulation subsystem

III. Analysis and tabulation pbase, which coosists of two sub-phases:

III.1 Classification

III.2 Application of avalysis procedures with report generation facilities and automatically syuthesized documentation.

Phase I, "Questionnaire build-up", is a user-friendly interface used to interrogate the user on the questionnaire entries, their attributes and, if applicable, tbeir associated possible answers. The attributes of an entry may be either one of those described in table (III). 
Table IIL. Data types used in the questionaaire analysis system

\begin{tabular}{|c|c|}
\hline Data type & Description \\
\hline Text & A plain text answer. \\
\hline Integer & An integer number. \\
\hline Real & A floating point number. \\
\hline Date & A date expression. \\
\hline Single option & $\begin{array}{l}\text { Refers to an index value of } 1 \text { up to the maximum number of } \\
\text { possible answers, eg. marital status. }\end{array}$ \\
\hline Multiple options & $\begin{array}{l}\text { Where more tban one answer are valid. In this type the user } \\
\text { ean weigh each answer with a number indicating its order, } \\
\text { eg. preferred transportation facility. }\end{array}$ \\
\hline Key & lodicating a corresponding data item. \\
\hline
\end{tabular}

This data type classification can hold true for most information systems in use and therefore suitable handliag mechanisus may be developed, validated and eventually reused whenever such data types are encountered.

Phase II, "Automatic generation of data manipulation subsystem", assembles tbe required data entry and editing procedures guided by the questionnaire description provided in phase I. It creates data files to hold collected data entries and customize a set of procedures to facilitate data entry and editing. Field names are coded internally and formatted to bold the corresponding data types without any user intervention to easure ease of operation and to eliminate any possible errors typically encountered in manual archive structuring. main tasks:

Phase II. "Analysis and tabulation", is then conccrued with performing two

1. It allows the user to filter some of his entered data to obtain subsets of the originally archived data if required. This data classification process is essential in specific studies.

2. It allows application of the analyzing procedures and synthesizes selfdocumeated reports.

\subsection{Characteristics of the user interface}

The user interface bas been designed bearing in mind that:

1. it must be user-friendly through the use of numerous help messages and pop-up menus for easy seleetion. Also, most data entries are being performed by selecting possible answers using oaly the arrow keys.

2. search criteria are being b silt using simple relational algebra where all operandi and operators are displayed in natural language rather than mathematical notation.

3. the user is able to customize the automatically generated reports by selecting whether he needs an automatically synthesized description of search classes, user defined eaptions, percentile calculations and their decimal digits, or a combination of all mentioned options. 
Manisoura Englnearing Journal (MEJ), Vo1.20, No.4, Dec. $1995 \quad$ E. 36

To fulfill the above requirements of the user interface, a number of routines have been selected from the repository to minimize the clerieal work required in data entry of hundreds of questionnaire forms with tens of entries. In case of data entry and/or update the user can select any questionnaire form and then navigate througb its entries until one is selected for editing. The system keeps track of the data types under consideration and then calls the appropriate data nauipulation procedures.

While specifying the required analyses, the user is asked to customize search elasses. A user defined caption is entered for the elass and thea a series of conditions are edited, in aatural language, to form the filtration criteria for the class.

\subsection{Implementation overview}

Figure (2) illustrates the user view of the proposed software system. The user interacts with the system at three stages:

1. requirements specification to enable the system to boild-up the questionnaire form and its entries.

2. eotry of collected forms using the automatically generated and/or assembled data bandling procedures.

3. analyses specification through user defined search classes using aatural language and simple relational algebra.

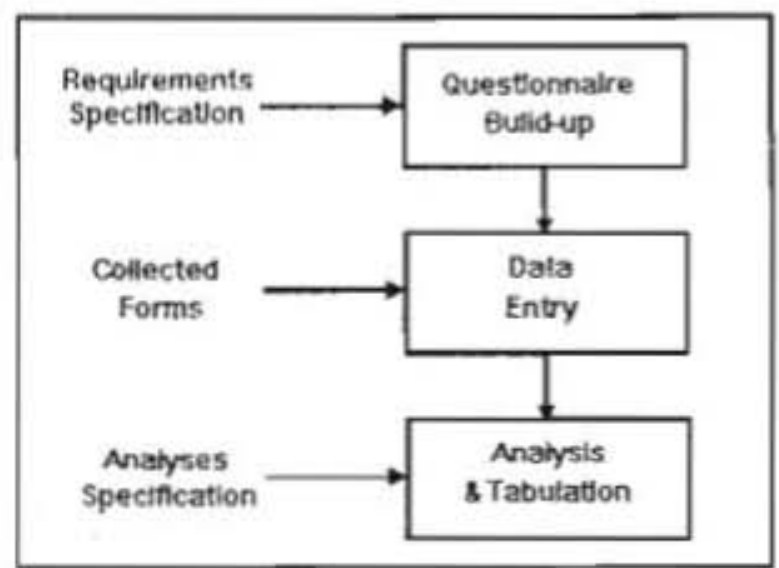

Figure 2, User view or QUTrE software system 
Figure (3) gives a schematic of the main components of QUTIE software system.

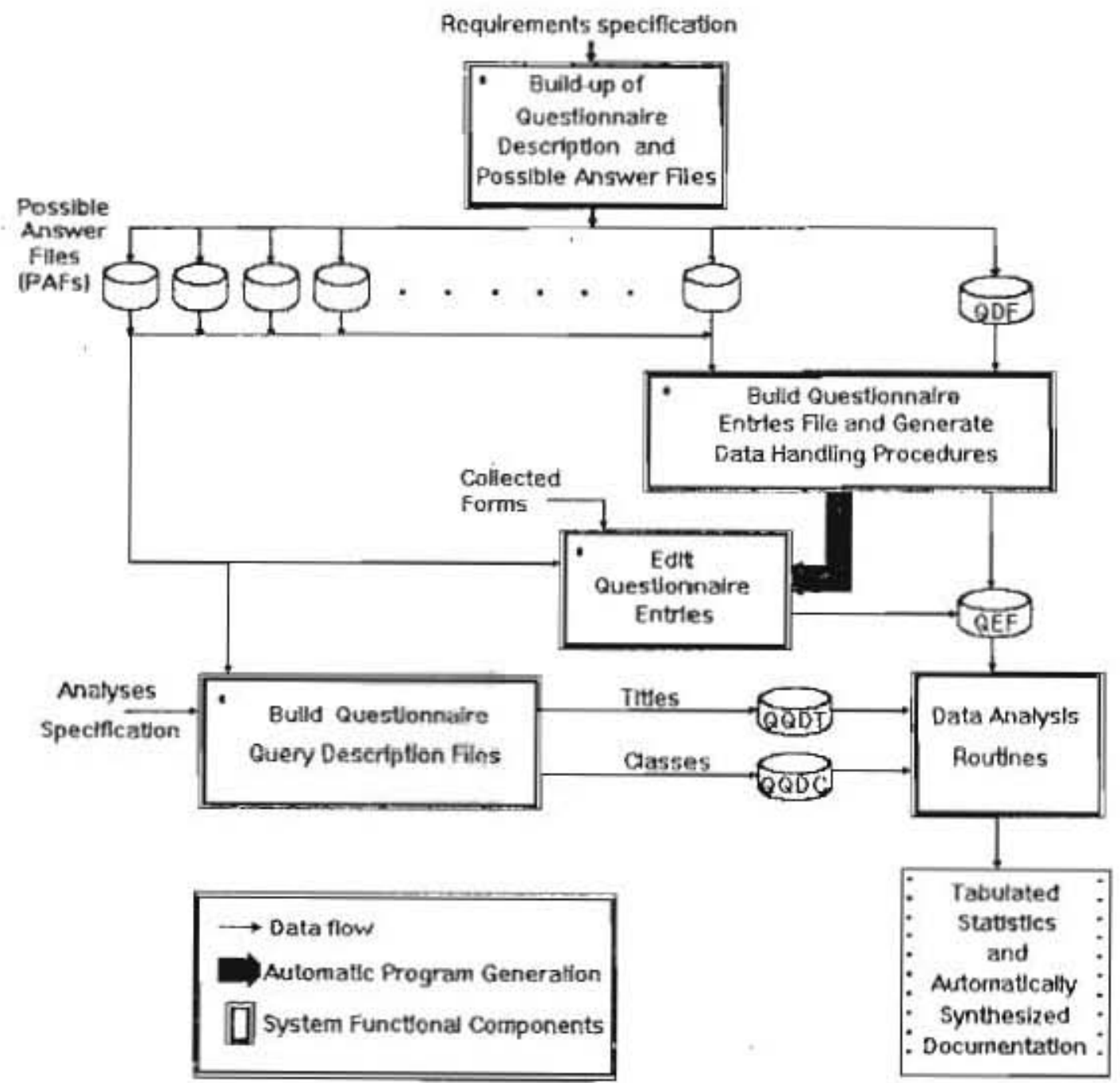

Figure 3. Main components of QUTIE software system.

(Automatically generated or repositery taken procedures)* 
According to the requirements specification, the system produces a Questionnaire Description File (QDF) and a set of Possible Answer Files (PAFs) for entries of single, multiple and key option types. The above files are then used to build a Questionnaire Entries File (QEF) to hold collected lata and customize data entry procedures to suit the used data types. The routine customization process is adaptive in the sense that any changes made to the questionnaire description file are mapped directly to the data entry procedures.

In questionnaire anaiyses specification, queries are stored as search classes and then used in the tabulation processes. They are assigned user defined captions (QQDT) for easy retrieval and for use in tabulation, and a query description is stored as a set of conditions formed in relational aigebra and stored internally as codes (QQDC) but displayed in natural language form. The analyzing routines then use the query descriptions given above to form criteria upon which search classes are formed in addition to automatically synthesized natural language documentation. Finally, tabulated forms are produced containing all or part of the above information as selected by the user.

Figure (3) empbasizes the automatically generated or repository taken procedures. The automatically generated subsystem consisted of 989 procedures and functions (Functional Components (FCs)) while the extra sdded procedures and functions consisted of 567 FCs. The percent automated part is therefore: $63.56 \%$.

\subsection{Dustrative example}

A hypothetical questionnaire form bas been designed to test the performance of the implemented system. The test is mainly directed to investigate the meritq of building software systems using the above described concepts. Inberent capabilities of the system are higblighted for assessing the gained benefits of such automatically generated systems. It must be emphasized here that figure (3) sbows the functional componeat clusters with captions related to the application example for illustrative purposes. However, these components are applicable to a wide class of similar information systems.

A set of 1000 questionnaire forms bas been stored. Data values bave been generated using a random number generator, bounded by meaningful limits, chosen according to the entries under consideration. Some human intervention was some times essential to force the data set to illustrate certain conditions. Table (IV) contains the chosen questionnaire entries and their attributes.

Following are some automatically generated output forms as samples of what could be obtained using the proposed system. Table (V) illustrates ten user defined searcb classes (shown only are user defined captions). 


\section{E. 39 S.K. Guirguis}

Table IV. Questionnaire entries and their attributes

\begin{tabular}{|c|c|c|}
\hline Entry & Attribute & Possible answers \\
\hline Employee name & Text & \\
\hline Employee Sex & Boolean & $\begin{array}{l}\text { MALE } \\
\text { FEMALE }\end{array}$ \\
\hline Birth Date of Employce & Date & \\
\hline Salary plus Incentives & Real & \\
\hline Marital Status & Single-option & $\begin{array}{l}\text { SINGLE } \\
\text { MARRIED } \\
\text { DIVORCED } \\
\text { WIDOW }\end{array}$ \\
\hline Number of Children & Integer & \\
\hline $\begin{array}{l}\text { Transportation facility } \\
\text { to reach firm }\end{array}$ & Multiple-options & $\begin{array}{l}\text { PRIVATE CAR } \\
\text { COMPANY BUS } \\
\text { PUBLIC BUS } \\
\text { UNDERGROUND } \\
\text { WAIKING } \\
\text { BICYCLE } \\
\text { MOTORCYCLE }\end{array}$ \\
\hline
\end{tabular}

Tabie V. User defined search classes

1 Male employees

2 Female employees

3 Employee name starts with SANDRA

4 Birth date later than 1-Jan-70

5 Single or divorced employees

6 Has more than 2 children

7 Preferred facility

8 Salary is less than $\$ 400$

9 Salary is between $\$ 400-600$

10 Salary is greater than $\$ 600$

Table (VT) illustrates a typical system output produced from tabulating four examples of occurrences of selected classes. While first and second sections of table (VT) illustrate classes composed of one condition, the third and fourth sections display multiple condition ciasses.

Table (VI) illustrates a system output that shows two examples of occurreaces of a certain class in another. Table (VII) gives cross tabulated classes wbile table (DX) gives the same table but with resetting the percentile calculation option. 
Table VI. Occurrences of a certain class

Occurrences of Class : I Male employecs

Synthesized Description :

Class : 1

Employee Sex IS MALE

Occurrences of Class : [1] Male employees $=572$

Percent Occurrences $=\mathbf{5 7 . 2 0} \%$

Total Cases $=1000$

Occurrences of Class : 4 Birthdate later than 1-Jan-70

Synthesized Description :

Class : 4

Birth Date of Employee GREATER THAN 70.01.01

Occurrences of Class : $[4]$ Birthdate later than $1-\sqrt{a n}-70=326$

Percent Occurrences $=32.60 \% \quad$ Total Cases $=1000$

Occurrences of Class : 5 Single or divorced employees

Synthesized Description :

Class : 5

Marital Status IS SINGLE OR Marital Status IS DIVORCED

Occurrcaces of Class : [5] Single or divorced employees $=500$

Percent Occurrences $=50.00 \%$

Total Cases $=1000$

Occurrences of Class : 7 Preferred facility

Syathesized Description :

Class : 7

Transportation facility to reach firm IS SUCH THAT :

PRIVATE CAR IS NOT SELECTED

AND COMPANY BUS IS SELECTED

AND BICYCLE IS NOT SELECTED

AND MOTORCYCLE IS NOT SELECTED

OR Transportation facility to reach firm IS SUCH THAT: PRIVATE CAR IS RANKED I

Occurrences of Class: [7] Preferred facility $=667$

Percent Occurrences $=66.70 \%$ 


\section{E.a1 S.X.Guirguis}

Table VII. Occurrences of a class in another

\begin{aligned} \hline Occurrences of Class : & 3 Employee name starts with SANDRA \\ IN Class : & 4 Birthdate later than 1-Jan-70 \end{aligned}

Syntbesized Description :

Class : 3

Employee name IS SANDRA

Class : 4

Birtb Date of Employee GREATER THAN 70.01.01

Occurrences of Class : [3] Employee vame starts with SANDRA IN Class : [4] Birthdate later than 1-Jan-70 IS = 47 OUT OF 326

Percent Occurrences $=14,42 \%$ Total Cases $=1000$

Occurrences of Class : 1 Male employees

IN Class : 5 Single or divorced employees

Synthesized Description :

Class : 1

Employee Sex IS MALE

Class : 5

Marital Status IS SINGLE OR

Marital Status IS DIVORCED

Occurrences of Class : [1] Male employees

IN Class : [5] Singie or divorced employees

IS $=285$ OUT OF 500

Percent Occurrences $=57.00 \%$ 


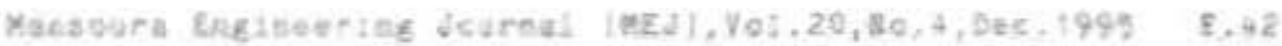

Tatile vist, Cross cabuistien of dasses

\section{Syadiesized Description}

Cruss Tabeiation of Classes:

Class : 1

Employer Ses IS Masy.

Class: 2

Emploger Sex IS FEMAL:

VExSUS Clastes :

Clans: 8

Salary pien formative INSS IRAN 400

Clan: 9

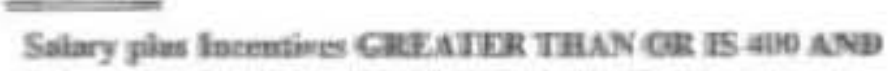

Selmery plus latentiven IXSS THAN OR IS 600

Class 2 ip

Clans a

Salury plas Incentivea GWE:ATER THAN 600

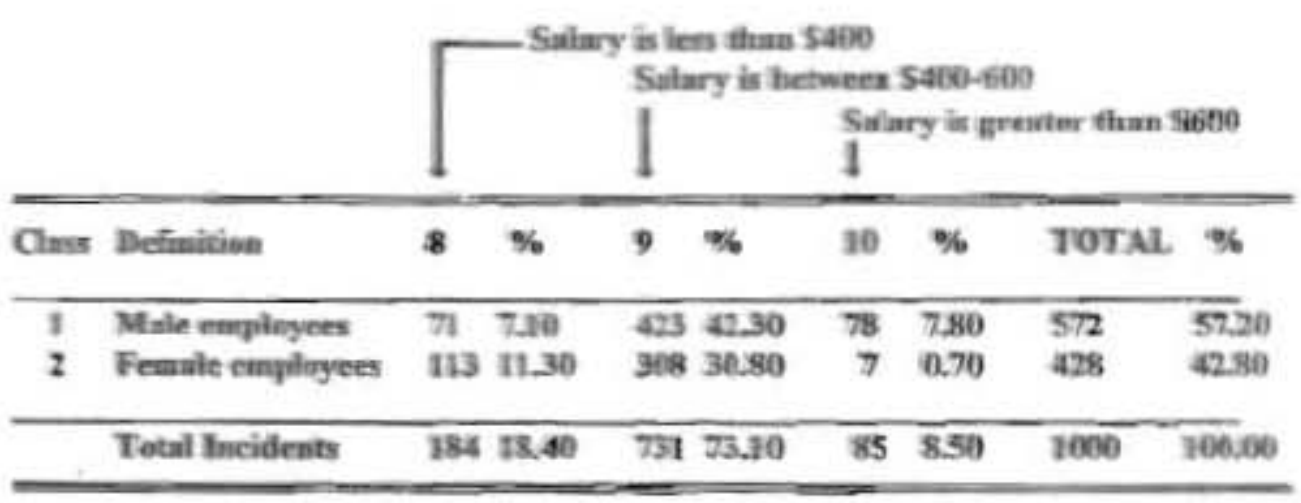


Table IX. Cross tabulation with resetting percentile caiculations

\begin{tabular}{|c|c|c|c|c|c|}
\hline \multirow[b]{2}{*}{ Class } & \multirow[b]{2}{*}{ Definition } & \multicolumn{4}{|c|}{$\begin{array}{l}\text { Salary is less than } \$ 400 \\
\text { Salary is between } \$ 400-600 \\
\square=\mid \begin{array}{l}\text { Salary is greater tban } \$ 600 \\
\downarrow\end{array}\end{array}$} \\
\hline & & 8 & 9 & 10 & TOTAL \\
\hline 1 & Male employees & 71 & 423 & 78 & 572 \\
\hline \multirow[t]{2}{*}{2} & Female empioyees & 113 & 308 & 7 & 428 \\
\hline & Total Incidents & 184 & 731 & 85 & 1000 \\
\hline
\end{tabular}

It is worth mentioning that all tables described above along with their syntbesized descriptions are automatically generated to emphasize the feature that the output is self-documented.

The system bas been put to practice by applying it to study the social impacts of the Sea Level Rise pbenomenon on people living is vuinerable areas [16]. Two districts in Alexandria city had been cbosen for the study, namely: Amreya and Semouha. A questionnaire form has been designed and tbe proposed software system has been used to nanipulate tbe collected forms. The results obtained via report generation and query formation kernels bave been successfully used in the study.

\subsection{Generalizing the approach}

The same procedures have been used to geverate the other four systems by using the concept of script files to describe data flows. Other complementary functions that bad to be constructed were added to fully cbaracterize a given software system.

Table (X) summarizes the number of automatically generated functional components and tbeir ratios to the total in each system. The ratios reflect bow mucb data manipulations are in such systems. It is noted that the number of functional components has becn increased in the latter systems along with increasing ratios of automation. This is attributed to the several amendments and refinements done during implementing the first software system. However, it must be noted that in (MSL) where domain dependent computations were required tbe value of $(\sigma / \Omega)$ was less than that of the others. 
Mansoura Englneerlng Journal (MEJ), Vo1.20, Mo.4,Dec.1995 E.42

Table $\mathrm{X}$. Automatically generated versus total functional components

\begin{tabular}{lrrr}
\hline System & $\sigma$ & $\Omega$ & $\sigma / \Omega \%$ \\
\hline QUTIE & 989 & 1556 & 63.56 \\
MSL & 1794 & 3483 & 51.51 \\
CLUC & 2781 & 4322 & 64.35 \\
ACS & 5088 & 6373 & 79.84 \\
SDO & 4944 & 6022 & 82.10 \\
\hline
\end{tabular}

Figure (4) illustrates the effect of $\alpha$ on $\theta$. As $\alpha$ increases due to either refinement of the repository "components or, on the contrary, the course production of complementary components, the value of $\theta$ decreases to a lowest limit of $(1-\sigma / \Omega)$.

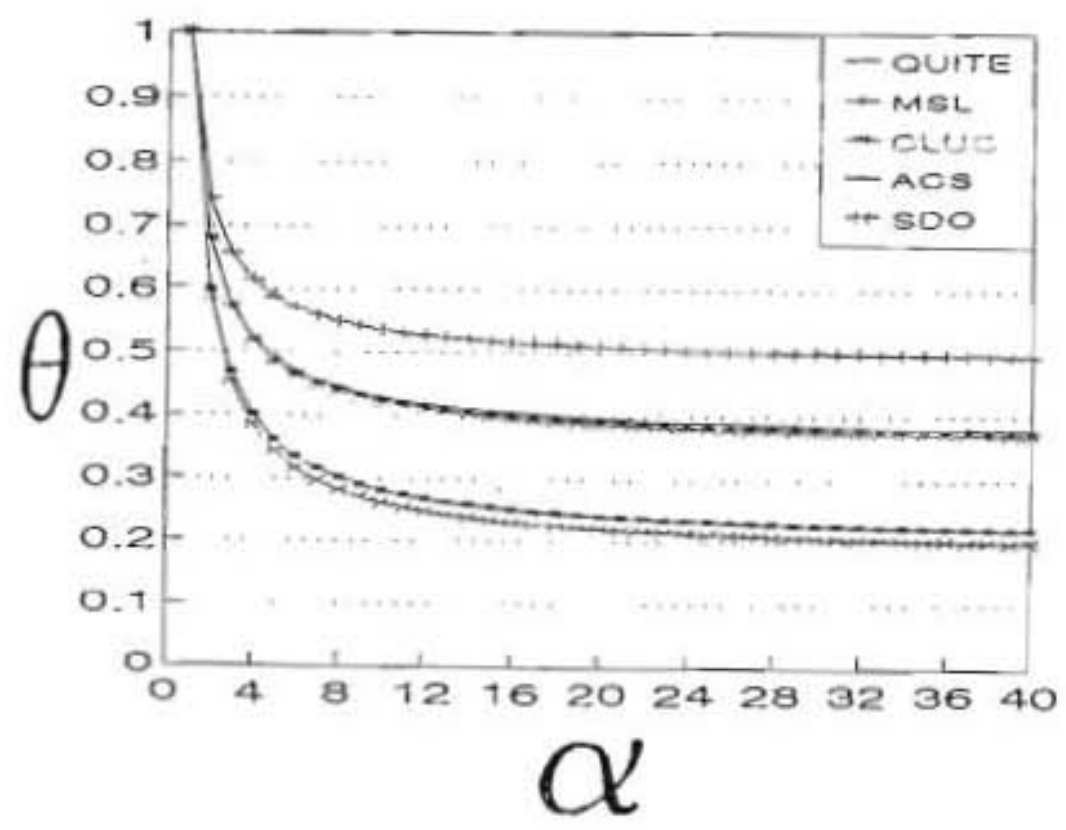

Figure 4. Effect of $\alpha$ on $\theta$ 


\section{CONCLUSION}

The aspects of software development productivity and the final product overall quality have been investigated in this paper. Seven key issues affecting the two aspects have been examined.

Relying on a repository of thoroughly cbecked reusable software components, had a profound effect on reducing the software development life cycle. The concept of using scripts greatly facilitated rapid software prototyping where a user approval bas always been obtained within a considerably short time.

Unifying data manipulation, query and report generation proeedures in a manner that is coherent with the user interface, resulted in both reducing the required development time and enbancing the overall working environment. The same data entry screens have been used for query formation and report generation. In query and report formation only some nuatebing patterus are entered for retrieving single events or use the very same pattern to generate a report. The above described approach requires the user to get acquainted with a limited set of sereen desigus that are ased in three different ways. On the other hand this approach substantially reduces the programming effort and time.

To some extent, the above described functional components are of comparable size and complexity, except for the MSL application. The development time of each FC is therefore approaching an average value of $(T)$ given by $\left(T=\Sigma t_{i} / \Omega\right)$ where $t_{i}$ is the development time of $\mathrm{FC}_{\mathrm{i}}$. As a rough estimate, it can be concluded from table $(\mathrm{X})$ tbat the development time has been reduced to range between 17.9-48.49\% with an average of $31.73 \%$, i.e, about one third of the required development time in classical systems design. However, tbe exact estimate is dependent on each individuat system according to its nature.

It is evident that maintainability has been practiced on a limited number of components rather than implementing a full system from scratch. Also, modifications are generally reduced since they are applied to a very limited set of scripts rather than the actual code.

Performance of the final product has been related to the level of automation in the development process. It is concluded tbat the continuous refinements made to the repository components would lead to decreasing the probability of faidure $P_{f}$ with a rate proportional to $\left(1 / \alpha^{2}\right)$.

All of the above mentioned issues are always aiming at reducing the time consumed tbrougbout the software development life-cycle and obtain as early results as possible from the proposed software system with reasonable quality.

One of the points whict seems to be missing in tbis context is wbat's accepted to be a formal requirement specification. It is noticed that this may be successful on the level of single programs or functions, and could be understood by software developers. However, on the level of systems this needs a great deal of research and review in order to involve the ultimate target: the end user. 
Nansoura Enzineering Jouraal (MEJ), Vol.20, No.4,Dec.1995 E.46

Also, metries are being applied to code segments in order to quantify their performance $[17,18$. Altougb metrics are also required ou the level of rystems, they are rather complieated and cumberseme to be practically applicable. For this issue, we suggest a potential solution and that's to spply appropriate metrica to the original scripts rather than the fully implemented software system.

\section{REFERECES}

[1] Coats R.B. and Vaeminke L (1987) Man-Compnter Interfaces, Blackwell Scientific Publications.

[2] Guirguis S.K., E-Racy M., Korany E. and Yehia S. (1993) Practicing Implementation of a Large Software System. Proceedings of Software Quality Masagement, SQM93, Southampton, U.K., 360-373.

[3] Rich C. and Waters R.C., (1988) Automatic Programining: Mytbs and Prospects. Computer, 40-51.

[4] Boiten E.A., Partsch H.A., Tuijnman D, and Volker N. (1992) How to Produce Correct Software - An Intreduction to Formal Specification and Programi Development by Transformations. The Computer Journal, Vol. 35, No. 6.

[5] Senmens L.T., France R.B. aad Docker T.W.G. (1992) Integrated Structured Analysis and Fermal Specification Techniques. The Computer Journal, Vol. 35, No. 6.

[6] Blackman M. and Jeffreys M. (1993), Quality Systems by Prototyping. Proceedings of Software Quality Managewent, SQM93, Southampton, U.K., 385-400.

[7] Buckley Y.J. and Poston R. (1984) Software Quality Assurance. IEEE Trans. Software Eag, Vol. SE-10, Ne. 1, 36-41.

[8] Caldiera G. and Basili V.R. (1991) Identifying and Qualifying Reusable Software Components. Computer, 61-70.

[9] [EF (1990) Information Engincering Facility, Technology Overview, Texas Instruments Incorporation.

[10] IEF (1990) Information Engineering Facility, Methodology Overview, Texas Instruments Incorporation.

[11) Lockhart R. (1993) On Statistics in Software Engineering Measurement, Software Quality Journal 2, 49-60.

[12] Macro A. and Buxton J. (1987) The Craft of Software Eaginering, Addison Wesley.

[13] Geist R., Offutt A.J. and Barris F.C. (1992) Estimation and Enhancenent of ReatTime Software Reliability through Mutation Analysis, DEE Traas. Computer, Vol. 41, 550-558.

[14] Nerusis M.J. (1985) SPSS/PC+ for the DBM PC/XT/AT.

[15] SGC (1986) Statistical Grapbics System. Ststistical Graphics Corporation.

[16] Dessouky S.M. (1993) Remote Sensing and Geographic Information Analysis of Clinatic Impact over Alexandria. M.Se. thesis, Institute of Graduate Studies \& Research, Alexasdria University.

[17] Garlick F.J. (1993) Planar Similarity - A New Syotbetic Metric. Proceediugs of Software Quality Management, SQM93, 503-516.

[18] Bently W.G. and Miller E.F. (1993) Ct Coverage - Initial Results. Software Quality Journat $2,29-47$. 
Appendix A. List of abbreviations

\begin{tabular}{ll}
\hline ACS & Assets Control System \\
CASE & Computer Aided Software Engineering \\
CLUC & Container Lading/Unloading Control \\
FC & Functional Component \\
MSL & Machine Service Log \\
MTBF & Mean Time Between Failures \\
MTTF & Mean Time To Fril \\
MTTR & Mean Ti ae To Repair \\
QBE & Query By Example \\
QDF & Questionasire Description File \\
QEF & Questionnaire Entries File \\
QQDC & $\quad$ Questionaire Query Description Classes \\
QQDT & Questionnaire Query Description Titles \\
QUTTE & Questionnaire Utilization in an Lntegrated Tabulation \\
SDO & Environment. \\
\hline \hline
\end{tabular}

